\title{
Enhanced water desalination performance through hierarchically-structured ceramic membranes
}

Tong Liu ${ }^{\mathrm{a}, \mathrm{b}, \mathrm{c}}$, Libin Lei ${ }^{\mathrm{b}}$, Jianqiang $\mathrm{Gu}^{\mathrm{c}}$, Yao Wang ${ }^{\mathrm{a}, \mathrm{b}, *}$, Louis Winnubst ${ }^{\mathrm{c}, \mathrm{d}}$, Chusheng $\mathrm{Chen}^{\mathrm{c}}$, Chunsong Ye ${ }^{\mathrm{a}}$, Fanglin Chen ${ }^{\mathrm{b}, *}$

${ }^{a}$ School of Power and Mechanical Engineering, Wuhan University, Wuhan, Hubei 430072, China

${ }^{\mathrm{b}}$ Department of Mechanical Engineering, University of South Carolina, Columbia, SC 29208, USA

${ }^{\mathrm{c}}$ CAS Key Laboratory of Materials for Energy Conversion and Department of Materials Science and Engineering, University of Science and Technology of China, Hefei, Anhui 230026, China

${ }^{\mathrm{d}}$ Inorganic Membranes, MESA+ Institute for Nanotechnology, University of Twente, P.O. Box 217, 7500 AE Enschede, The Netherlands

Corresponding Authors

* Tel: +86 27 68772264, Email: pmewy@whu.edu.cn (Y. Wang); Tel: +1 803777 4875, Email: chenfa@cec.sc.edu $($ F. Chen)

\begin{abstract}
Developments of membrane water desalination are impeded by low water vapor flux across the membrane. We present an innovative membrane design to significantly enhance the water vapor flux. A bilayer zirconia-based membrane with a thick hierarchically-structured support and a thin functional layer is prepared using a combined freeze drying tape casting and screen printing method. The hierarchically-structured YSZ support has a porosity of $42.6 \%$, pores of $4.5 \mu \mathrm{m}$ or larger, and a relatively low tortuosity of 1.58 along the thickness direction. The bilayer membrane is then converted from naturally hydrophilic to hydrophobic via grafting with a fluoroalkylsilane. A water flux of $28.7 \mathrm{Lm}^{-2} \mathrm{~h}^{-1}$ and a salt rejection of $99.5 \%$ are achieved by exposing the functional layer to $80{ }^{\circ} \mathrm{C}$ salt water of $2 \mathrm{wt} . \% \mathrm{NaCl}$ and the support layer to $20{ }^{\circ} \mathrm{C}$ distilled water. These results are the best performing ones for ceramic membranes in direct contact membrane distillation operation.
\end{abstract}


Keywords: membrane distillation; seawater desalination; hierarchical oriented pores; freeze drying tape casting; X-ray computed tomography 


\section{Introduction}

According to the millennium development report released by the United Nations in 2009, human beings around the world are experiencing a more and more severe fresh water shortage[1]. The conventional seawater desalination technologies suffering from high energy-consumption and high investment impede their large-scale applications, especially in the developing countries and isolated islands [2-4]. For this reason, it is urgently required to develop and explore cost-effective and energy-efficient alternative seawater desalination technologies to produce fresh water. Membrane distillation (MD) has been considered as a low capital cost and energy efficient alternative to conventional desalination technologies, because it can operate at atmospheric pressure and low temperature, and utilize the low-grade or waste heat derived from solar energy, wind energy and industrial waste heat, etc.[5, 6].

As it is well known, a porous hydrophobic membrane is needed to separate pure water from the seawater via MD process [5-7]. During the MD operation, liquid water at the hot side (feed side) of the membrane will evaporate at the interface of the hot water and membrane. The water vapor will subsequently pass through the porous membrane driven by the water vapor partial pressure difference across the membrane. Finally, the water vapor will condense into liquid water at the cold side (permeate side) of the membrane. At the same time, because the membrane used is hydrophobic, liquid water as well as dissolved minerals and other ingredients cannot permeate through the membrane. Therefore, pure water can be obtained at the permeate side of the membrane. However, in contrast to its great potentials and advantages, its relatively low water flux compared to the MSF and RO hinders its large-scale implementation and deployment by the industry $[8,9]$. Therefore, to accelerate the practical application of this process, research on flux enhancement should be intensively investigated.

Currently, most of the membranes used for MD process are made of polymers [10-12], such as polyvinylidenedifluoride (PVDF) and polystyrene (PS). However, due to their poor thermal, mechanical and chemical stability during the operation, these polymeric membranes represent significant bottleneck for widespread commercialization of this technology. Compared with polymers, ceramic materials exhibit excellent chemical, structural and thermal stability upon exposure to the salt water [13], indicating that the ceramic membrane is suitable for practical 
MD application [14-19]. It cannot be neglected that most ceramic membranes are hydrophilic in nature due to the existence of hydroxyl groups $(-\mathrm{OH})$ on the surface, which will prevent them being directly applied in a MD unit. One possible way to solve this problem is grafting hydrophobic groups on the membranes via surface modification, and thus converting the hydrophilic membranes to hydrophobic ones. Because of the presence of hydrolysable and hydrophobic groups, fluoroalkylsilanes (FAS) has been considered as one of the most effective hydrophobic agent, and been intensively grafted on the surface of the ceramic membranes to manipulate their hydrophobicity [19-23]. During the grafting procedure, the hydrolysable groups of FAS will react with the hydroxyl groups on the surface of the membrane, and therefore a hydrophobic membrane can be obtained for MD application.

For a MD process, water vapor transfer through a membrane is strongly influenced by its microstructural parameters, such as thickness, porosity, pore size (distribution) and tortuosity $[5,24,25]$, and a bilayer supported membrane is preferred for MD application by considering the trade-off between the water flux and mechanical strength. Recently, the supports with high tortuosity and low porosity have been shown to limit their water flux [26]. Consequently, there is an urgent need to explore and develop an innovative and cost-effective method to prepare a support with higher porosity but lower tortuosity, therefore to enhance the water flux and accelerate practical application of MD process. In recent years, freeze drying tape casting method, which has been used in the fields of solid oxide cells and gas separation membranes [27-31], has been proven to be an effective and unique technique to fabricate support membranes with significantly low tortuosity and remarkably improved performance, and implying that the freeze drying tape casting method is expected to fabricate the hierarchically-structured supports to facilitate mass transport during MD operation, holding a great promise for high-performance MD desalination application. According to the water vapor cooling-down method, the MD process can be classified into four different configurations[5]. By survey of the previous studies, it can be found that among these different MD processes, direct contact membrane distillation (DCMD) is the widely adopted configuration due to its simplicity and reasonably high water flux [32-37]. Therefore, in this study, DCMD configuration is used to evaluate the separation properties of the hydrophobic ceramic membranes prepared using the freeze drying tape casting method. 
In this work, freeze drying tape casting method is utilized to fabricate a supported bilayer YSZ membrane with a thin YSZ functional layer and a thick hierarchically-structured YSZ support. The 2 dimensional (2D) and 3D microstructure of the bilayer membranes is examined using the scanning electron microscope (SEM) and X-ray computed tomography (XCT), respectively. Microstructural effects on the DCMD performance of these hydrophobic YSZ membranes with bilayer microstructure are systematically evaluated.

\section{Experimental}

\subsection{Fabrication of YSZ planar membranes}

Hierarchically-structured yttria-stabilized zirconia (YSZ) membrane supports were prepared using freezing drying tape casting method as described in detail in the previous reports [27, 38]. An aqueous based YSZ (TZ-8YS, Tosoh Company, Japan) slurry was prepared with an ammonium polyacrylate dispersant (Darvan C-N, R. T. Vanderbilt Co. Inc., USA), a viscosity modulator (Vanzan, R. T. Vanderbilt Co. Inc., USA) and an acrylic latex emulsion binder (Duramax HA-12, Rohm\&Haas, USA). YSZ powder loading of $67 \mathrm{wt} \%$ was used. The ammonium polyacrylate dispersant was mixed with water and YSZ powders for the first $2 \mathrm{~h}$ ball milling. Subsequently, the binder and viscosity modulator were added for the second $2 \mathrm{~h}$ ball milling. Before freeze tape casting, the slurry was de-aired by vacuum for 10 min. A freezing bed temperature of $-70{ }^{\circ} \mathrm{C}$, a blade height of $1.5 \mathrm{~mm}$ and a pulling rate of 20 $\mathrm{mm} \min ^{-1}$ of the Mylar polymer film were adopted in this work. After the YSZ tape was frozen for about $30 \mathrm{~min}$ on the Mylar film in the casting bed, the YSZ substrate was punched into pellets with a diameter of about $40 \mathrm{~mm}$. The pellets were dried in a vacuum freeze dryer at $-30{ }^{\circ} \mathrm{C}$ at $2.4 \mathrm{~Pa}$ for one day. Subsequently the pellets were pre-sintered with a heating rate of $2{ }^{\circ} \mathrm{C} \mathrm{min}{ }^{-1}$ and a dwell time of $5 \mathrm{~h}$ at $1100{ }^{\circ} \mathrm{C}$ to achieve sufficient mechanical strength for subsequent coating of the YSZ functional layer. This YSZ coating was achieved by screen printing a homogeneous YSZ slurry made by ball milling for $2 \mathrm{~h}$ an 1:1.5 weight ratio YSZ:alpha-terpilenol (Alfa Aesar, USA) mixture. The bilayer membrane was co-sintered at $1250{ }^{\circ} \mathrm{C}$ for $5 \mathrm{~h}$ with a heating and cooling rate of $2{ }^{\circ} \mathrm{C} \mathrm{min}^{-1}$. After this sintering procedure the effective area for DCMD tests was $4.5 \mathrm{~cm}^{2}$.

\subsection{Grafting procedure}


In this work, the grafting procedure chosen was based on the literatures previously reported [15-18]. The sintered YSZ membranes were immersed into acetone, dried for $2 \mathrm{~h}$ at $80{ }^{\circ} \mathrm{C}$ and then cleaned via ultrasonication in ethanol and water respectively and dried for $2 \mathrm{~h}$ at $100{ }^{\circ} \mathrm{C}$. Subsequently the membranes were immersed into a 2 wt.\% $1 \mathrm{H}, 1 \mathrm{H}, 2 \mathrm{H}, 2 \mathrm{H}-\mathrm{Perfluorooctyltriethoxysilane}$ (FAS, 98\% purity, Sigma-Aldrich, USA) in ethanol at room temperature and maintained in the solution for $12 \mathrm{~h}$ to allow the coupling reaction to occur. After immersion, the membranes were dried at $100{ }^{\circ} \mathrm{C}$ with a dwell time of 6h to be ready for the DCMD experiments.

\subsection{Characterization}

The 2D microstructure of the hierarchically-structured YSZ membranes and the YSZ support was characterized using SEM (Zeiss Ultra Plus FESEM, Germany), while the 3D microstructure of the YSZ support was characterized using X-ray microscopy (Xradia, USA) and analyzed by an in-house Matlab code. Details to construct the 3D structure are described in a previous report [28]. The surface morphology of the membranes was characterized by atomic force microscopy (AFM, MPF-3D-SA, Asylum Research Inc.). Contact angle measurements were performed on the surface of the FAS-modified YSZ functional layer by the water drop method using a contact angle meter (SL200B, Solon Tech Co. Ltd., Shanghai, China).

Pure water flux through the bi-layer YSZ membranes with an effective diameter of 12.0 $\mathrm{mm}$ were measured using a home-made setup, similar to that described in Ref. [17].

The water vapor flux was studied on a home-built DCMD equipment, as schematically shown in Fig. 1. The DCMD measurements in this study were repeated by five samples, and the experimental errors in these trials were the variance of the experimental results derived from the different samples. Three different aqueous $\mathrm{NaCl}$ solutions with concentrations of 2, 4 and 6 wt.\% were used as feed solution. The temperature of the salt solution in the feed tank was consecutively controlled at $50,60,70$ and $80{ }^{\circ} \mathrm{C}$. Salt water was circulated in the system at a flow rate of $100 \mathrm{~L} \mathrm{~h}^{-1}$ (equivalent to $27.7 \mathrm{~mL} \mathrm{~s}^{-1}$ ) by using a small circulating pump and a flow meter. Before the salt water entered the feed side of the membrane unit, the feed was heated by, a heater and controlled by a thermocouple in order to achieve a feed temperature at a temperature with an accuracy $<2{ }^{\circ} \mathrm{C}$ of the setting value of the feed tank. Distilled water 
passed through the cold channel (permeate side) at a flow rate of $100 \mathrm{~L} \mathrm{~h}^{-1}$ and a chiller after the cold channel was used to maintain the temperature of distilled water of the permeate side at $20 \pm 2{ }^{\circ} \mathrm{C}$ in all experiments. The water fluxes through the membranes were quantified by measuring the water weight increment using an electronic balance. At the same time, in order to keep the $\mathrm{NaCl}$ concentration of the feed constant, a small circulating pump and an electronic balance were used to compensate the permeated water. The conductivities of the salt water $\left(C_{s}\right)$ and permeated water $\left(C_{f}\right)$ were measured by a conductivity meter (FE30, Mettler Toledo). The $\mathrm{NaCl}$ rejection rate $(R)$ was calculated by the following equation:

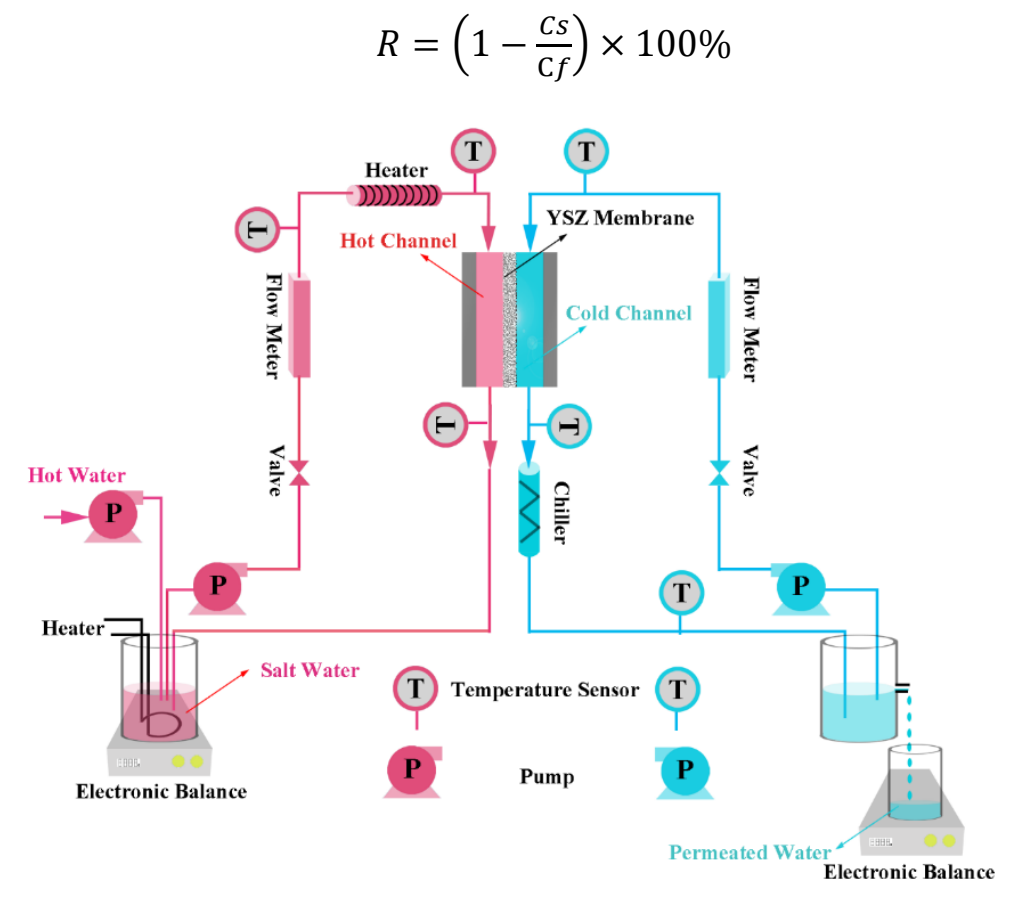

Fig.1. The piping and instrumentation diagram of the DCMD setup.

\section{Results and discussion}

\subsection{Morphology of the YSZ membranes}

Fig. 2 shows a cross-sectional SEM image of the pre-sintered YSZ support. After subsequent removal of ice crystals and pre-sintering at $1100{ }^{\circ} \mathrm{C}$, a support with continuously hierarchically-structured in one direction oriented pores/channels was achieved. The size of the pores/channels decreases from $\sim 30 \mu \mathrm{m}$ on the bottom surface to $1 \sim 5 \mu \mathrm{m}$ on the top surface, which is attributed to the continuous temperature gradient from the bottom of the casted tape $\left(-70{ }^{\circ} \mathrm{C}\right)$ to the ambient air along the thickness direction [38]. As shown in Fig. 2, many of these hierarchically-structured channels show the typical microstructure of materials prepared 
using the freeze drying tape casting method and span the entire cross-section of the support[27, 28, 31, 38]. This microstructure results in a low tortuosity, with a value close to 1 , which is beneficial for fast gas and solvent transport through the support layer.

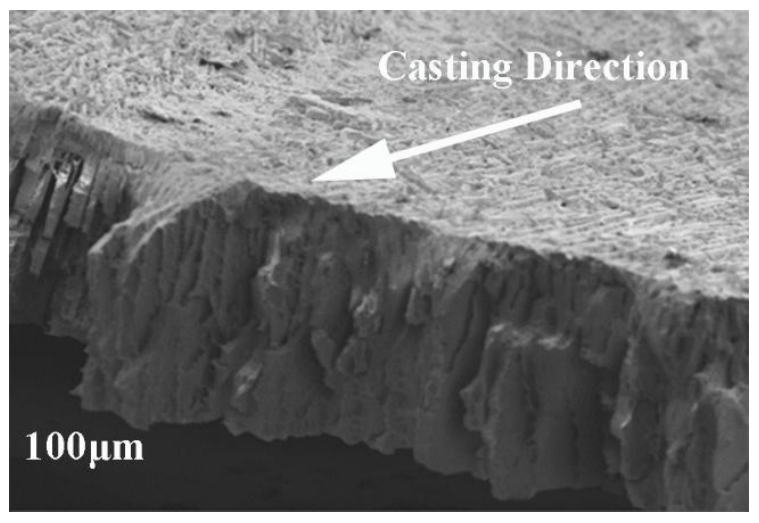

Fig. 2. The cross-sectional SEM image of the YSZ support pre-sintered at $1100{ }^{\circ} \mathrm{C}$.

To further investigate the microstructure of the support with the hierarchically-structured pores/channels, 3D X-ray microscope combined with an in-house Matlab code is applied as a non-destructive virtual sectioning of the support to reveal the internal 3D morphology. The spatial resolution of XCT in this study is set at $4.45 \mu \mathrm{m}$ to reconstruct the entire microstructure in the thickness direction $(\sim 590 \mu \mathrm{m})$. Fig. 3 A and B show the reconstructed 3D microstructural images for a domain with a dimension of $1.12 \times 0.45 \times 0.59 \mathrm{~mm}^{3}$, reconstructed from the top surface with micron-sized pores and bottom surface with macro-pores, respectively. In Fig. 3 A-B, the solid phase (YSZ) appears blue, while the pores (hierarchically-structured oriented pores/channels) show up green, and the pore size is calculated to be less than $5 \mu \mathrm{m}$ on the top part but larger than $30 \mu \mathrm{m}$ on the bottom part. Fig. 3C exhibits the porosity distribution of the hierarchically-structured oriented pores/channels of the YSZ support in the thickness direction shown in Fig. 3A. The porosity of the YSZ support gradually increased from $10 \%$ to $64 \%$ along the $z$-axis with an average porosity of $43 \%$. The tortuosity of the pores in the thickness direction is calculated to be 1.58 , which is close to the results reported using the freezing drying tape casting method as described by Chen et al[27, 28], and much smaller than that for the membranes with sponge-like pores prepared by the a conventional tape casting method, which have a tortuosity of typically $4 \sim 10$ [39]. It is well known that mass transfer in porous media is hindered by a high tortuosity and low porosity[40]. Therefore, the hierarchically-structured YSZ support with relative low 
tortuosity and high porosity will have no adverse impact on mass transfer in the hierarchically-structured YSZ support, so creating favorable conditions for enhanced mass transfer.
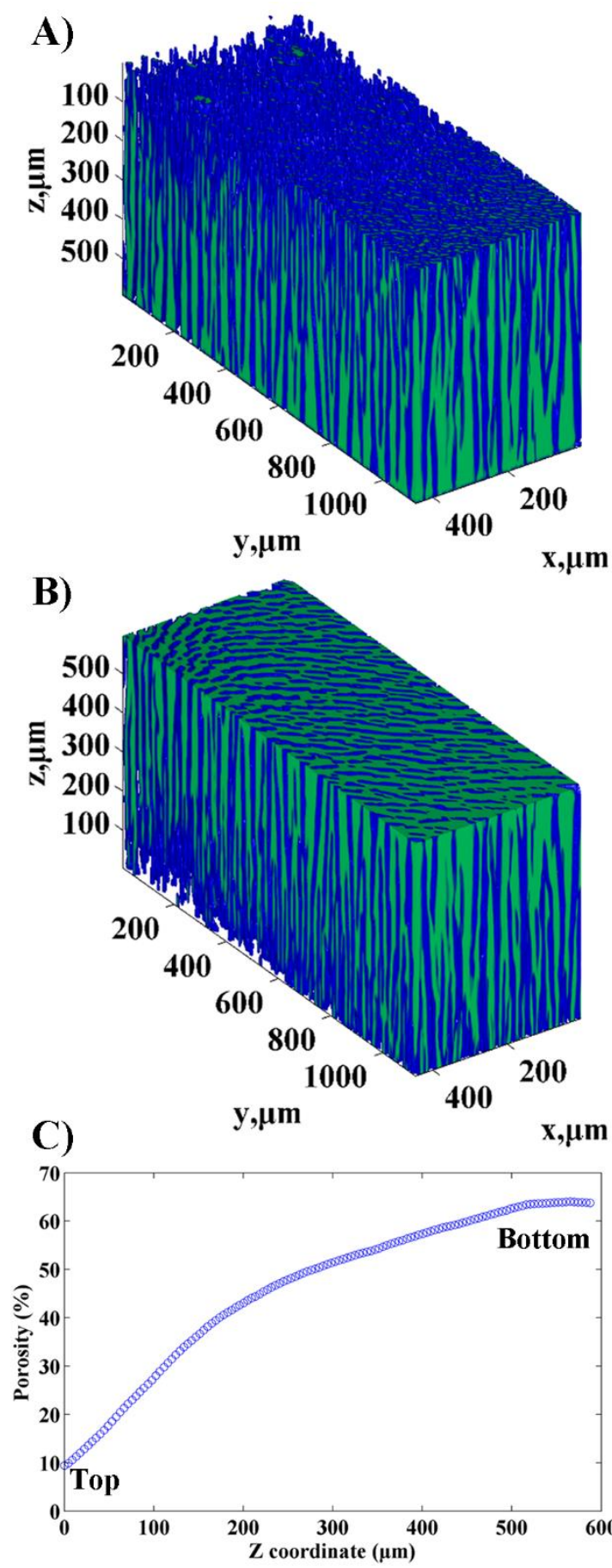

Fig. 3. Reconstructed 3D microstructural images of the YSZ support reconstructed from A) the top surface with micron-sized pores and B) the bottom surface with macro-pores. The blue and green regions represent solid and pore phases, respectively. C) Distribution of the local porosity along $z$-axis (thickness direction) from the top surface to the bottom surface. 


\subsection{Properties of bilayer YSZ membranes}

Fig. 4A shows a cross-sectional SEM image of the bilayer YSZ membrane prepared using the combined freeze drying tape casting and screen printing method. It can be seen from this figure that a YSZ functional layer with thickness of $\sim 20 \mu \mathrm{m}$ was successfully coated on the YSZ support. SEM images at larger magnification show that the YSZ functional layer consisted of homogeneous pores without pores larger than $1 \mu \mathrm{m}$ (Fig. 4B), demonstrating that the YSZ bilayer membrane is suitable for DCMD application.

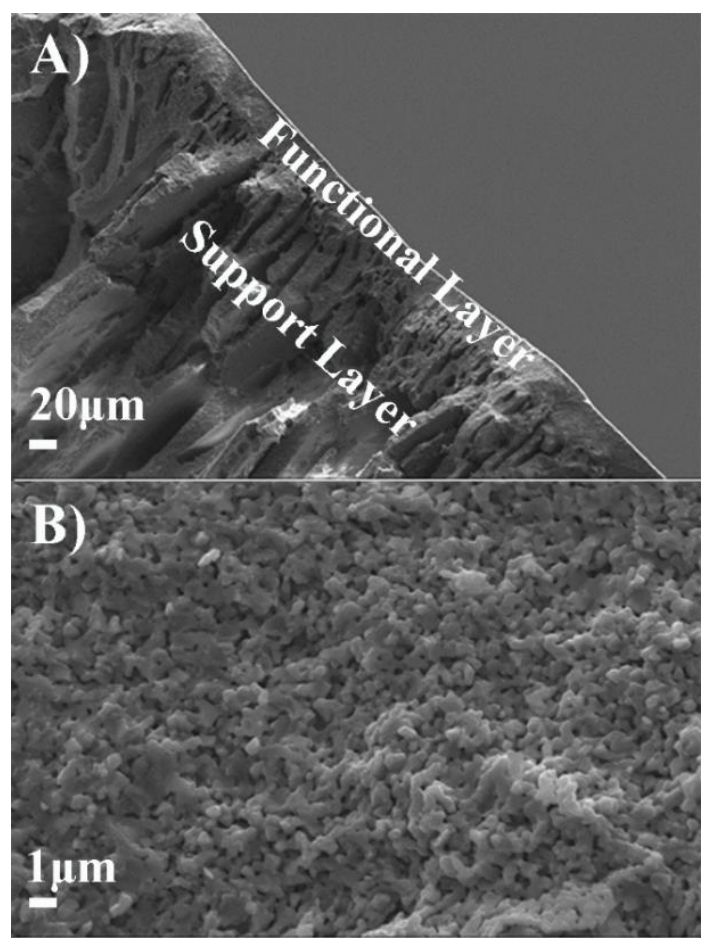

Fig. 4. SEM images of A) cross section of the bi-layered YSZ membrane and B) the functional layer.

The wetting behavior of the membranes was evaluated by measuring the water contact angle of the surface of the membrane. The water contact angle for the fresh sample was in the range of $34 \sim 38^{\circ}$ with an average of $36^{\circ}$, which is caused by the porosity and natural hydrophilic character of its surface due to the presence of hydroxyl groups $(-\mathrm{OH})$ on the membrane surface (Fig. 5A-a). However, after grafting of FAS on the hydrophilic membrane, the contact angle was increased to $133-138^{\circ}$ with an average of $135^{\circ}$, revealing that the membrane surfaces were successfully converted to hydrophobic via surface modification, which is attributed to the introduced long hydrophobic FAS chain (Fig. 5B-b) on the membrane surface[15, 20, 23, 41]. 
Fig. 6 shows the typical AFM images of the surface of the functional layer of the membranes before and after FAS grafting. These AFM images indicate that although the contact angle has been increased from the range of $34 \sim 38^{\circ}$ with an average of $36^{\circ}$ to $133-138^{\circ}$ with an average of $135^{\circ}$, no obvious changes on the surface morphology can be observed.
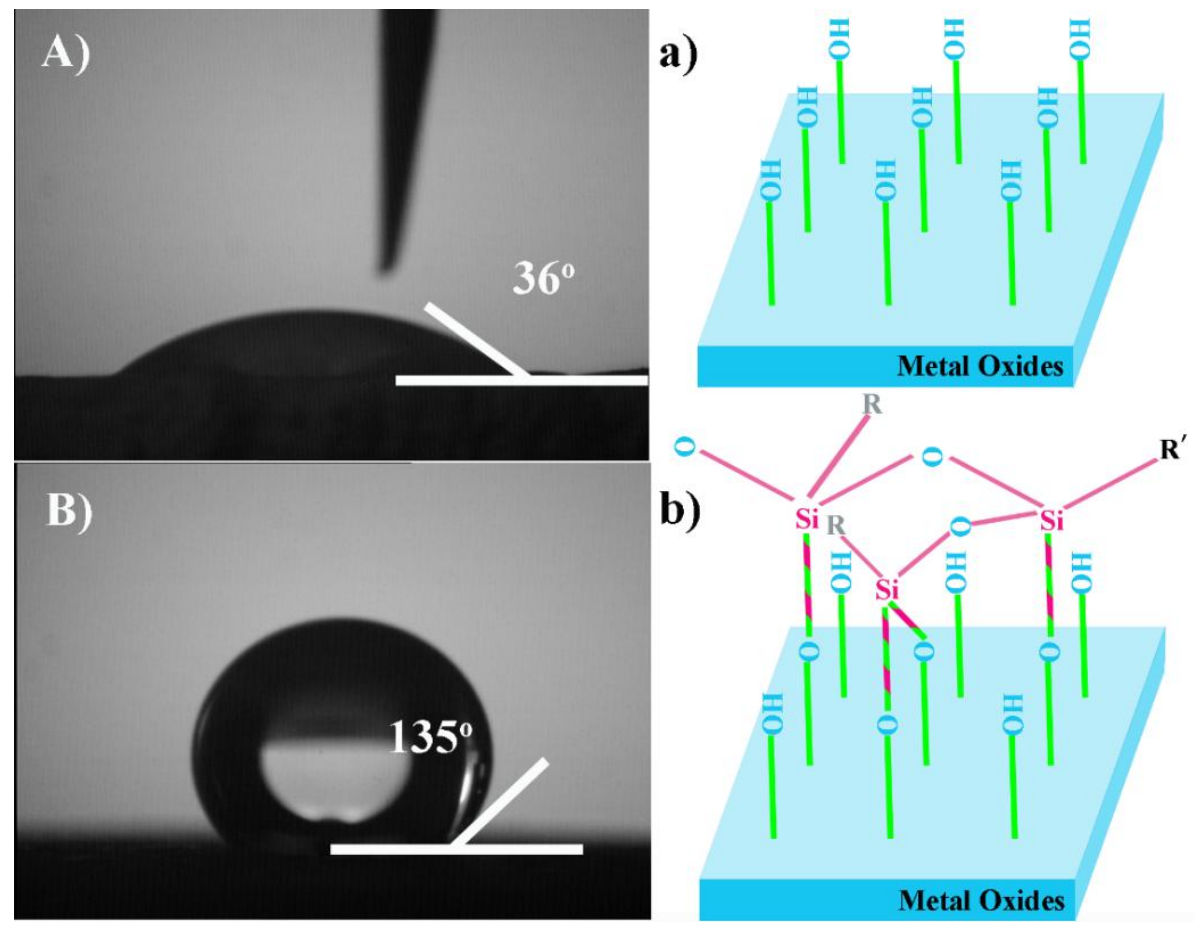

Fig. 5. Wetting behavior of the membranes, A-a) fresh membrane, B-b) grafted membrane, A-B) water contact angle, a-b) schematic diagram of the membrane surface. $R$ and $R^{\prime}$ both represent the hydrophobic groups (Fig. 5b).
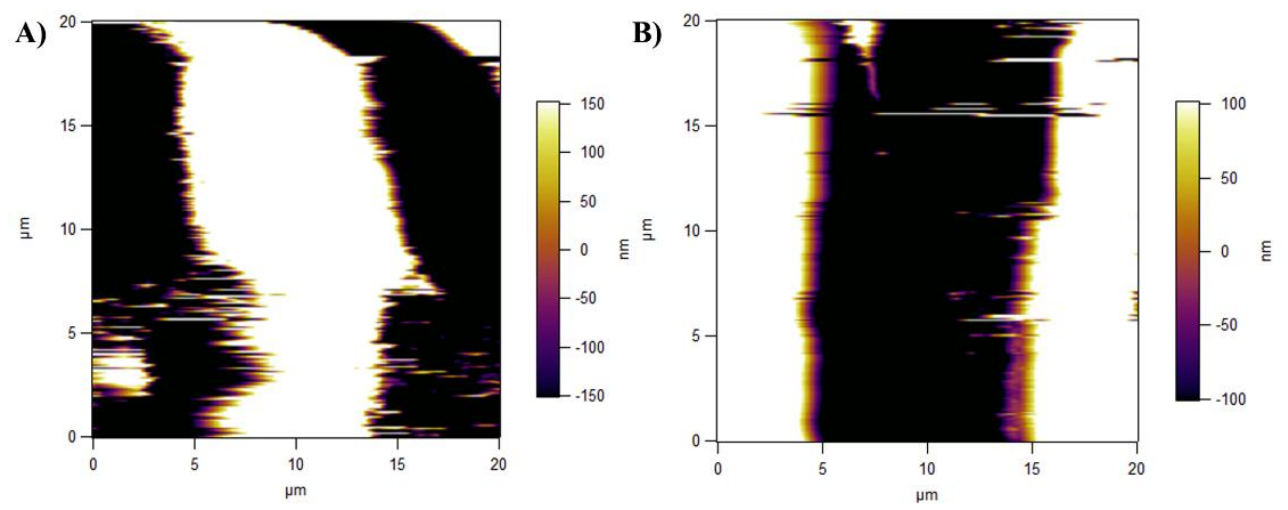

Fig. 6. AFM images of the membranes, A) fresh membrane, and B) grafted membrane.

Fig. 7 shows the pure water flux as a function of the transmembrane pressure of the bi-layer YSZ membrane before and after grafting with FAS. A pure water permeability of $1.4 \pm 0.1 \times 10^{4}$ $\mathrm{Lm}^{-2} \mathrm{~h}^{-1} \mathrm{bar}^{-1}$ (equivalent to $1.4 \pm 0.1 \times 10^{2} \mathrm{Lm}^{-2} \mathrm{~h}^{-1} \mathrm{kPa}^{-1}$ ) is obtained from the experimental data shown in Fig. 7, which is much higher than porous multi-layer ceramics membranes, even 
higher than the results reported for asymmetric membranes prepared using the phase-inversion method, confirming that this bi-layer YSZ membrane is expected to be less permeable to gases and liquids. It can be also found that the pure water permeability remained zero even a transmembrane pressure of $220 \mathrm{kPa}$ is applied upon the membrane, implying that this grafted bi-layer membrane can operate under the MD conditions at transmembrane pressure of up to $220 \mathrm{kPa}$, which is called the liquid entry pressure $(L E P w)$.

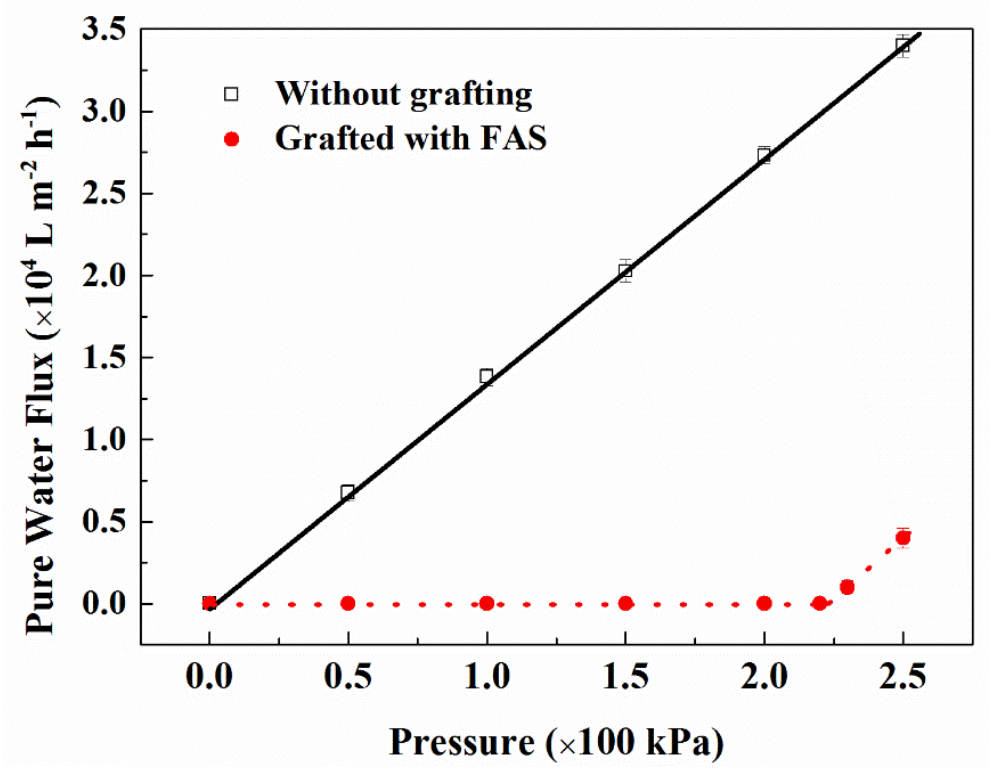

Fig. 7. The pure water flux of the ungrafted and grafted bi-layer YSZ membranes.

\subsection{Water desalination performance}

On the basis of the above findings, water permeation measurements were carried out to further investigate the potential of this novel bilayer membranes for high-performance DCMD application. In this study, DCMD performance of FAS-grafted hierarchically-structured hydrophobic bilayer YSZ membrane was conducted at a series of feed temperature $\left(T_{f}\right)$ and $\mathrm{NaCl}$ concentrations while the temperature of the entrance of the permeate channel $\left(T_{p}\right)$ was fixed at $20{ }^{\circ} \mathrm{C}$. Fig. 8 illustrates the water flux through the membranes as functions of $T_{f}$ and $\mathrm{NaCl}$ concentrations of 2-6 wt.\%. In all cases the salt rejection was more than $99 \%$. The water flux increases with increasing $T_{f}$ and decreasing salt concentration. Particularly, a significant increase in water flux is observed from $7.2 \pm 0.5$ to $28.7 \pm 0.5 \mathrm{~L} \mathrm{~m}^{-2} \mathrm{~h}^{-1}$ (the latter is equivalent to $688.8 \pm 12.0 \mathrm{~L} \mathrm{~m}^{-2}$ day $^{-1}$ ) by increasing $T_{f}$ from 50 to $80{ }^{\circ} \mathrm{C}$ at a salt concentration of 2 wt. $\%$ and $T_{p}$ of $20^{\circ} \mathrm{C}$.

As we all know, during the DCMD operation, the feed and permeate liquid must not 
penetrate the membrane pores so the applied pressure should not exceed a limit, $L E P w$, which highly depends on the maximum pore size, the membrane hydrophobicity and is also related to the salt concentration of the feed. According to the Young-Laplace equation, $L E P w$ can be estimated from Eq. (2) [42]

$$
L E P w=P_{f, H_{2} O}-P_{p, H_{2} O}=\frac{-B \gamma \cos \theta}{r_{\max }}
$$

where $P_{f, H_{2} O}$ and $P_{p_{, H_{2} O} O}$ are the hydraulic pressure on the feed and permeate side, respectively, $B$ is a geometric pore coefficient (tortuosity), $\gamma$ is the liquid surface tension, $\theta$ the contact angle, and $r_{\max }$ the maximum pore size. As a result, a membrane having a large contact angle (high hydrophobicity) and small pore size, is preferred in order to obtain a high $L E P w$ value. In this work, the contact angle $\theta$ is $133-138^{\circ}$ with an average of $135^{\circ}$, the geometric pore coefficient $B$ of the functional layer is $4 \sim 10$ because the functional layer for the membrane is composed of unordered sponge-like pores while the B value of the support is calculated to be 1.58 due to the hierarchical structure with large oriented pores, and the maximum pore size is smaller than $1 \mu \mathrm{m}$. In addition, the liquid surface tension, $\gamma$, at $80{ }^{\circ} \mathrm{C}$ is $62 \times 10^{-3} \mathrm{Nm}^{-1}$. By applying Eq. (2) a $L E P w$ of $176 \mathrm{kPa}$ is calculated for this hierarchically-structured hydrophobic bilayer YSZ membrane.

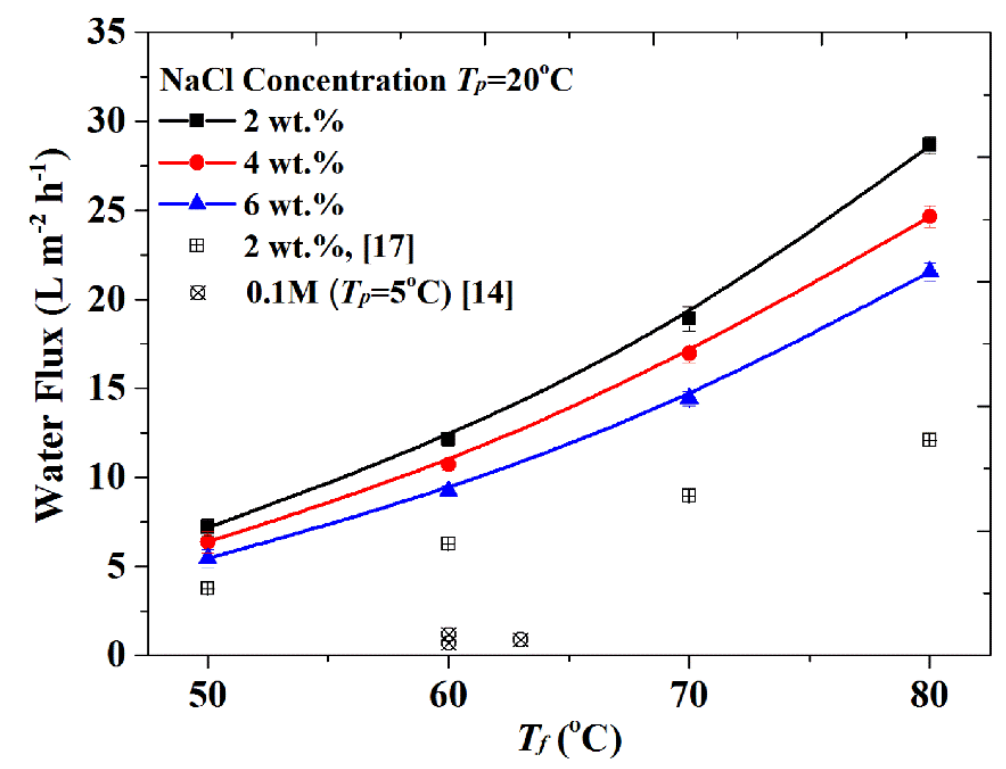

Fig. 8. Water flux as functions of the temperature of the feed side and the $\mathrm{NaCl}$ concentration.

The driving force for mass transfer in the DCMD operation is the difference between the water vapor partial pressure $\left(\Delta P_{\mathrm{H}_{2} \mathrm{O}}\right)$ at the two sides of the membrane (cold channel and hot 
channel as shown in Fig. 1). According to the Antoine equation, the saturated water vapor partial pressure $\left(P_{x, \mathrm{H}_{2} \mathrm{O}}\right)$ at the membrane can be expressed as[43]

$$
\log \left(P_{H_{2} O}^{*}\right)(\mathrm{Pa})=10.195-\frac{1730.63}{T+233.43}
$$

where $P_{\mathrm{H}_{2} \mathrm{O}}^{*}$ is the saturated water vapor partial pressure at both sides of the membrane, $T$ is the temperature $\left({ }^{\circ} \mathrm{C}\right)$. Meanwhile, Raoult's law states that the partial water vapor pressure $\left(P_{x, \mathrm{H}_{2} O}(x=f, p)\right)$ of an $\mathrm{NaCl}$ solution is equal to the saturated water vapor pressure multiplied by the mole fraction $\left(x_{\mathrm{H}_{2} \mathrm{O}}\right)$, . The saturated water partial vapor pressures of the feed side $\left(P_{f, \mathrm{H}_{2} \mathrm{O}}\right)$ or permeate side $\left(P_{p, \mathrm{H}_{2} \mathrm{O}}\right)$ can therefore be described by[43]

$$
P_{x, H_{2} \mathrm{O}}(x=f, p)=P_{\mathrm{H}_{2} \mathrm{O}}^{*} \times x_{\mathrm{H}_{2} \mathrm{O}}
$$

It can be seen from Eqs. (3) and (4) that $P_{f, \mathrm{H}_{2} \mathrm{O}}$ and $P_{p, \mathrm{H}_{2} \mathrm{O}}$ both show an exponential increase with increasing operating temperature. Taking distilled water as an example, when increasing $T_{f}$ from $50{ }^{\circ} \mathrm{C}$ to $80{ }^{\circ} \mathrm{C}$, the $P_{f, H_{2} O}$ increases from 12.3 to $47.3 \mathrm{kPa}$. At the same time, since the $T_{p}$ is fixed at $20{ }^{\circ} \mathrm{C}, P_{p, H_{2} O}$ is kept at $2.3 \mathrm{kPa}$. Therefore, at a permeate temperature of $20{ }^{\circ} \mathrm{C}$ and feed temperatures of 50 and $80{ }^{\circ} \mathrm{C}$, the water vapor pressure differences across the membrane are 10 and $45 \mathrm{kPa}$, respectively. In a DCMD unit, salt water instead of distilled water is fed into the hot channel, resulting in a lower $P_{f, \mathrm{H}_{2} \mathrm{O}}$ and $\Delta P_{\mathrm{H}_{2} \mathrm{O}}$ (see Eqs. (3) and (4)). Therefore, $\Delta P_{\mathrm{H}_{2} \mathrm{O}}$ across the membrane is less than $45 \mathrm{kPa}$ and subsequently significantly lower than the calculated $L E P w$ value of $176 \mathrm{kPa}$ and the experimental result $(L E P w>200 \mathrm{kPa})$, implying that the hydrophobic bilayer YSZ membrane is suitable for DCMD application as studied in this work.

In this work, during all DCMD tests the salt rejection was above $99.5 \%$, also confirming that the $\Delta P_{\mathrm{H}_{2} \mathrm{O}}$ across the membrane was lower than the limit $(L E P w)$. Furthermore, during the contact angle measurement, it was found that the contact angle kept constant $\left(\sim 135^{\circ}\right)$ after 10-hour condensation reaction, which is shorter than that $(12 \mathrm{~h})$ used in this study. These results demonstrate that the pores in the YSZ functional layer (Fig. 4B) are small $(<1 \mu \mathrm{m})$ and that a complete grafting of FAS was achieved (Fig. 5B).

The transmembrane mass flux $\left(N_{m}\right)$ in the DCMD operation can be written as[44]

$$
N_{m}=K_{m}\left(P_{f, H_{2} O}-P_{p, H_{2} O}\right)=K_{m} \Delta P_{H_{2} O}
$$




$$
\text { or } \quad K_{m}=\frac{N_{m}}{P_{f, \mathrm{H}_{2} \mathrm{O}}-P_{p, \mathrm{H}_{2} \mathrm{O}}}=\frac{N_{m}}{\Delta P_{\mathrm{H}_{2} \mathrm{O}}}
$$

where $K_{m}$ is the intrinsic mass transfer coefficient, which is dependent on the operating temperature and pressure, and is assumed to be constant in many cases[44, 45]. By increasing $T_{f}$ from 50 to $80{ }^{\circ} \mathrm{C}$, the water vapor pressure difference $\left(\Delta P_{\mathrm{H}_{2} \mathrm{O}}\right)$ over the membrane increases significantly (from 10 to $45 \mathrm{kPa}$, as calculated by the Antoine equation), resulting in a remarkable increase in driving force for water vapor transfer through the membrane, and therefore leading to a profound increases in water flux $\left(N_{m}\right)$ (Eq. (5)). In this work, based on the experimental results shown in Fig. 8 , the $K_{m}$ values at $50{ }^{\circ} \mathrm{C} / 20{ }^{\circ} \mathrm{C}$ and $80{ }^{\circ} \mathrm{C} / 20{ }^{\circ} \mathrm{C}$ temperature gradients are calculated to be 0.72 and $0.64 \mathrm{~L} \mathrm{~m}^{-2} \mathrm{~h}^{-1} \mathrm{kPa}^{-1}$, respectively, demonstrating that the experimental $K_{m}$ value is not a constant value but will decrease slightly with increasing the feed temperature, which is possibly attributed to the increased temperature concentration in the feed side with increasing $T_{f}[44,45]$.

It can also be seen from Fig. 8 that at all temperatures, increasing the $\mathrm{NaCl}$ concentration at the feed side result in a decrease in water flux. This phenomenon can be explained by Raoult's law[43], which states that higher salt concentrations lead to decreased water vapor pressure. However, even at the highest $\mathrm{NaCl}$ concentration of $6 \mathrm{wt} . \%$, at $80{ }^{\circ} \mathrm{C}$ the water flux still maintains $21.6 \pm 0.5 \mathrm{~L} \mathrm{~m}^{-2} \mathrm{~h}^{-1}$, indicating that the hierarchically-structured hydrophobic bilayer YSZ membrane is an attractive membrane for seawater desalination via the DCMD process.

By comparing these results with literature data as given in [14], it can be observed that the water fluxes obtained in our study are significantly higher than that of the other ceramic membranes having a more symmetric pore structure[14]. For example, at a $60{ }^{\circ} \mathrm{C} / 20{ }^{\circ} \mathrm{C}$ temperature gradient and a salt concentration of $6 \mathrm{wt}$. \%, a water flux of $9.2 \pm 0.3 \mathrm{~L} \mathrm{~m}^{-2} \mathrm{~h}^{-1}$ is obtained (see Fig. 8), which is more than 10 times higher than that of a zirconia membrane $\left(0.7 \mathrm{~L} \mathrm{~m}^{-2} \mathrm{~h}^{-1}\right)$ at the $60^{\circ} \mathrm{C} / 5{ }^{\circ} \mathrm{C}$ temperature gradient and a salt concentration of $0.1 \mathrm{M} \mathrm{NaCl}$ solution (equivalent to $5.8 \mathrm{wt} . \%$ )[14]. This difference is attributed to the remarkably smaller thickness of the functional layer in our case $(20 \mu \mathrm{m}$ instead of $1500 \mu \mathrm{m})$ and thus a decreased water vapor transport resistance through the membrane bulk. It should also be pointed out that although the bilayer YSZ membrane with a total thickness of $600 \mu \mathrm{m}$ is three times thicker than the $\mathrm{Si}_{3} \mathrm{~N}_{4}$ hollow fibers with finger-like macro-pores, its water fluxes are $137 \%$ higher than the latter[17], demonstrating that the bilayer membrane structure prepared using the 
freeze drying tape casting, , is favorable for mass transfer in the bulk of the membrane and even better than that prepared using the phase inversion method[16].

Finally, the stability of the water flux of the hydrophobic YSZ membranes under different $\mathrm{NaCl}$ concentrations at a feed temperature of $80{ }^{\circ} \mathrm{C}$ is studied and the results are given in Fig. 9. At each stage, the exposure time is $210 \mathrm{~min}$ and the water flux was recorded as a function of the elapsed time with an interval of $30 \mathrm{~min}$. A total stability test of 630 minutes is applied and no adverse effect on water flux was observed, demonstrating that the hierarchically-structured hydrophobic bilayer YSZ bilayer membranes can be used for seawater desalination application via a DCMD process.

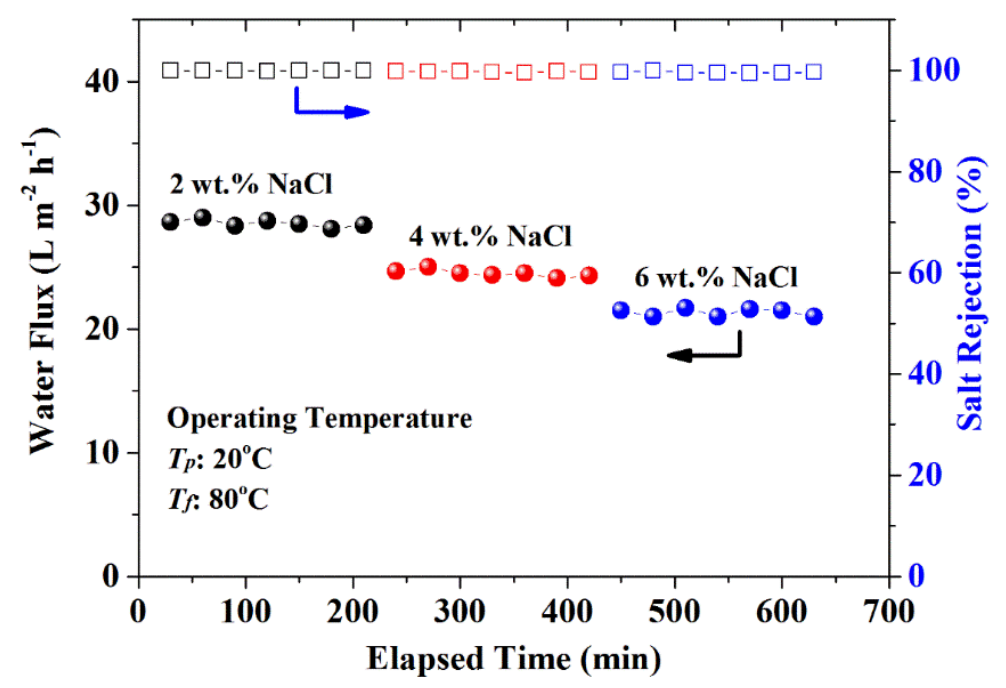

Fig. 9. Overview of test results obtained for the YSZ bilayer membrane plotted as a function of the elapsed time. Shown are the average water fluxes, recorded at $80{ }^{\circ} \mathrm{C} / 20{ }^{\circ} \mathrm{C}$ temperature gradient.

\section{Conclusions}

A novel bilayer YSZ membrane, consisting of a thin functional layer with micron-sized pores and a thick support layer with hierarchically-structured oriented macro-pores, has been successfully prepared by a combined freeze drying tape casting and screen printing method. The $2 \mathrm{D}$ and $3 \mathrm{D}$ microstructure show that this novel membrane holds the promise to significantly decrease the mass transfer resistance in the membrane and thus dramatically enhances the water flux in desalination by applying direct contact membrane distillation (DCMD) experiments. A high water flux is achieved, and at an $80{ }^{\circ} \mathrm{C} / 20{ }^{\circ} \mathrm{C}$ temperature gradient, using an aqueous solution of $2 \mathrm{wt} . \% \mathrm{NaCl}$ solution, the water flux reaches a value 
of $28.7 \pm 0 . .5 \mathrm{~L} \mathrm{~m}^{-2} \mathrm{~h}^{-1}$ (equivalent to $688.8 \pm 12.0 \mathrm{~L} \mathrm{~m}^{-2} \mathrm{day}^{-1}$ ), while the salt retention remains more than 99\%. This demonstrates that this novel bilayer YSZ membrane is an ideal membrane structure for high-performance DCMD applications.

\section{Acknowledgements}

We're grateful to the financial support from the U.S. National Science Foundation (grand number DMR-1210792), Natural Science Foundation of China (grand numbers 21271164, 51502207, 51602228), Natural Science Foundation of Jiangsu Province of China (grand number BK20160380), Natural Science Foundation of Hubei Province of China (grand number 2016CFB243), the Fundamental Research Funds for the Central University (grand numbers 2042015kf0043, 2042016kf0022), the China Postdoctoral Science Foundation (grand number 2016M590712), and the Opening Project of CAS Key Laboratory of Materials for Energy Conversion (grand number KF2016003). 


\section{References}

[1] U. N. Department of Economic, U. N. Department of Public Information, The Millennium Development Goals Report 2009. United Nations Publications.

[2] C. Li, Y. Goswami, E. Stefanakos, Solar assisted sea water desalination: a review, Renew. Sust. Energ. Rev., 19 (2013) 136-163.

[3] B. Peñate, L. García-Rodríguez, Current trends and future prospects in the design of seawater reverse osmosis desalination technology, Desalination, 284 (2012) 1-8.

[4] A. Pérez-González, A. Urtiaga, R. Ibáñez, I. Ortiz, State of the art and review on the treatment technologies of water reverse osmosis concentrates, Water Res., 46 (2012) 267-283.

[5] A. Alkhudhiri, N. Darwish, N. Hilal, Membrane distillation: a comprehensive review, Desalination, 287 (2012) 2-18.

[6] M.R. Qtaishat, F. Banat, Desalination by solar powered membrane distillation systems, Desalination, 308 (2013) 186-197.

[7] H.-C. Kim, J. Shin, S. Won, J.-Y. Lee, S.K. Maeng, K.G. Song, Membrane distillation combined with an anaerobic moving bed biofilm reactor for treating municipal wastewater, Water Res., 71 (2015) 97-106.

[8] M. El-Bourawi, Z. Ding, R. Ma, M. Khayet, A framework for better understanding membrane distillation separation process, J. Membrane Sci., 285 (2006) 4-29.

[9] A.K. An, J. Guo, S. Jeong, E.-J. Lee, S.A.A. Tabatabai, T. Leiknes, High flux and antifouling properties of negatively charged membrane for dyeing wastewater treatment by membrane distillation, Water Res., 103 (2016) 362-371.

[10] M.E. Leitch, C. Li, O. Ikkala, M.S. Mauter, G.V. Lowry, Bacterial nanocellulose aerogel membranes: novel high-porosity materials for membrane distillation, Environ. Sci. Technol., 3 (2016) 85-91.

[11] J.H. Kim, S.H. Park, M.J. Lee, S.M. Lee, W.H. Lee, K.H. Lee, N.R. Kang, H.J. Jo, J.F. Kim, E. Drioli, Thermally rearranged polymer membranes for desalination, Energy Environ. Sci., 9 (2016) 878-884.

[12] D. Hou, J. Wang, X. Sun, Z. Ji, Z. Luan, Preparation and properties of PVDF composite 
hollow fiber membranes for desalination through direct contact membrane distillation, $\mathrm{J}$. Membrane Sci., 405 (2012) 185-200.

[13] S. Benfer, U. Popp, H. Richter, C. Siewert, G. Tomandl, Development and characterization of ceramic nanofiltration membranes, Sep. Purif. Technol., 22 (2001) 231-237.

[14] A. Larbot, L. Gazagnes, S. Krajewski, M. Bukowska, W. Kujawski, Water desalination using ceramic membrane distillation, Desalination, 168 (2004) 367-372.

[15] H. Fang, J. Gao, H. Wang, C. Chen, Hydrophobic porous alumina hollow fiber for water desalination via membrane distillation process, J. Membrane Sci., 403 (2012) 41-46.

[16] C. Ren, H. Fang, J. Gu, L. Winnubst, C. Chen, Preparation and characterization of hydrophobic alumina planar membranes for water desalination, J. Euro. Ceram. Soc., 35 (2015) 723-730.

[17] J.-W. Zhang, H. Fang, J.-W. Wang, L.-Y. Hao, X. Xu, C.-S. Chen, Preparation and characterization of silicon nitride hollow fiber membranes for seawater desalination, J. Membrane Sci., 450 (2014) 197-206.

[18] J.-W. Zhang, H. Fang, L.-Y. Hao, X. Xu, C.-S. Chen, Preparation of silicon nitride hollow fibre membrane for desalination, Mater. Lett., 68 (2012) 457-459.

[19] S. Cerneaux, I. Strużyńska, W.M. Kujawski, M. Persin, A. Larbot, Comparison of various membrane distillation methods for desalination using hydrophobic ceramic membranes, J. Membrane Sci., 337 (2009) 55-60.

[20] J. Kujawa, W. Kujawski, S. Koter, A. Rozicka, S. Cerneaux, M. Persin, A. Larbot, Efficiency of grafting of $\mathrm{Al} 2 \mathrm{O} 3, \mathrm{TiO} 2$ and $\mathrm{ZrO} 2$ powders by perfluoroalkylsilanes, Colloid. Surface. A, 420 (2013) 64-73.

[21] J. Kujawa, S. Cerneaux, S. Koter, W. Kujawski, Highly Efficient Hydrophobic Titania Ceramic Membranes for Water Desalination, ACS Appl. Mater. Interfaces, 6 (2014) 14223-14230.

[22] J. Kujawa, S. Cerneaux, W. Kujawski, M. Bryjak, J. Kujawski, How To Functionalize Ceramics by Perfluoroalkylsilanes for Membrane Separation Process? Properties and Application of Hydrophobized Ceramic Membranes, ACS Appl. Mater. Interfaces, 8 (2016) 7564-7577. 
[23] J. Kujawa, S. Cerneaux, W. Kujawski, Characterization of the surface modification process of $\mathrm{Al}_{2} \mathrm{O}_{3}, \mathrm{TiO}_{2}$ and $\mathrm{ZrO}_{2}$ powders by PFAS molecules, Colloid. Surface. A, 447 (2014) 14-22.

[24] P. Wang, T.-S. Chung, Recent advances in membrane distillation processes: membrane development, configuration design and application exploring, J. Membrane Sci., 474 (2015) 39-56.

[25] P. Wang, M.M. Teoh, T.S. Chung, Morphological architecture of dual-layer hollow fiber for membrane distillation with higher desalination performance, Water Res., 45 (2011) $5489-5500$.

[26] M.K. Souhaimi, T. Matsuura, Membrane Distillation: Principles and Applications, Elsevier, Amsterdam, The Netherlands, 2011.

[27] Y. Chen, Y. Lin, Y. Zhang, S. Wang, D. Su, Z. Yang, M. Han, F. Chen, Low temperature solid oxide fuel cells with hierarchically porous cathode nano-network, Nano Energy, 8 (2014) 25-33.

[28] Y. Chen, Y. Zhang, J. Baker, P. Majumdar, Z. Yang, M. Han, F. Chen, Hierarchically oriented macroporous anode-supported solid oxide fuel cell with thin ceria electrolyte film, ACS Appl. Mater. Interfaces, 6 (2014) 5130-5136.

[29] C. Gaudillere, J. Garcia-Fayos, M. Balaguer, J.M. Serra, Enhanced oxygen separation through robust freeze-cast bilayered dual-phase membranes, ChemSusChem, 7 (2014) 2554-2561.

[30] C. Gaudillere, J. Garcia-Fayos, J.M. Serra, Enhancing oxygen permeation through hierarchically-structured perovskite membranes elaborated by freeze-casting, J. Mater. Chem. A, 2 (2014) 3828-3833.

[31] T. Liu, Y. Chen, S. Fang, L. Lei, Y. Wang, C. Ren, F. Chen, A dual-phase bilayer oxygen permeable membrane with hierarchically porous structure fabricated by freeze-drying tape-casting method, J. Membrane Sci., 520 (2016) 354-363.

[32] L.M. Camacho, L. Dumée, J. Zhang, J.-d. Li, M. Duke, J. Gomez, S. Gray, Advances in membrane distillation for water desalination and purification applications, Water, 5 (2013) 94-196.

[33] M.M.A. Shirazi, A. Kargari, A review on application of membrane distillation (MD) 
process for wastewater treatment, J. Membrane Sci. Res., 1 (2015) 101-112.

[34] K. Kezia, J. Lee, M. Weeks, S. Kentish, Direct contact membrane distillation for the concentration of saline dairy effluent, Water Res., 81 (2015) 167-177.

[35] A. Khalifa, H. Ahmad, M. Antar, T. Laoui, M. Khayet, Experimental and theoretical investigations on water desalination using direct contact membrane distillation, Desalination, 404 (2017) 22-34.

[36] F. Eleiwi, N. Ghaffour, A.S. Alsaadi, L. Francis, T.M. Laleg-Kirati, Dynamic modeling and experimental validation for direct contact membrane distillation (DCMD) process, Desalination, 384 (2016) 1-11.

[37] B.B. Ashoor, S. Mansour, A. Giwa, S.W.H. V. Dufour, Principles and applications of direct contact membrane distillation (DCMD): A comprehensive review, Desalination, 398 (2016) 222-246.

[38] S.W. Sofie, Fabrication of functionally graded and aligned porosity in thin ceramic substrates with the novel freeze-tape-casting process, J. Am. Ceram. Soc., 90 (2007) 2024-2031.

[39] K. Lindqvist, E. Lidén, Preparation of alumina membranes by tape casting and dip coating, J. Euro. Ceram. Soc., 17 (1997) 359-366.

[40] R.G. Carbonell, S. Whitaker, Heat and Mass Transfer in Porous Media, in: Fundamentals of Transport Phenomena in Porous Media, Springer, 1984, pp. 121-198.

[41] Z.-Q. Dong, B.-J. Wang, X.-h. Ma, Y.-M. Wei, Z.-L. Xu, FAS grafted electrospun poly(vinyl alcohol) nanofiber membranes with robust superhydrophobicity for membrane distillation, ACS Appl. Mater. Interfaces, 7 (2015) 22652-22659.

[42] A. Franken, J. Nolten, M. Mulder, D. Bargeman, C. Smolders, Wetting criteria for the applicability of membrane distillation, J. Membrane Sci., 33 (1987) 315-328.

[43] J.R. Elliott, C.T. Lira, Introductory Chemical Engineering Thermodynamics, Prentice Hall PTR, Upper Saddle River, NJ, 1999.

[44] R.W. Schofield, A.G. Fane, C.J.D. Fell, R. Macoun, Factors affecting flux in membrane distillation, Desalination, 77 (1990) 279-294.

[45] H. Yu, X. Yang, R. Wang, A.G. Fane, Numerical simulation of heat and mass transfer in direct membrane distillation in a hollow fiber module with laminar flow, J. Membrane 
Sci., 384 (2011) 107-116. 


\section{Figure Captions}

Fig.1. The piping and instrumentation diagram of the DCMD setup.

Fig. 2. The cross-sectional SEM image of the YSZ support pre-sintered at $1100{ }^{\circ} \mathrm{C}$.

Fig. 3. Reconstructed 3D microstructural images of the YSZ support reconstructed from A) the top surface with micron-sized pores and B) the bottom surface with macro-pores. The blue and green regions represent solid and pore phases, respectively. C) Distribution of the local porosity along $z$-axis (thickness direction) from the top surface to the bottom surface.

Fig. 4. SEM images of A) cross section of the bi-layered YSZ membrane and B) the functional layer.

Fig. 5. Wetting behavior of the membranes, A-a) fresh membrane, B-b) grafted membrane, A-B) water contact angle, a-b) schematic diagram of the membrane surface. $R$ and $R^{\prime}$ both represent the hydrophobic groups (Fig. 5b).

Fig. 6. AFM images of the membranes, A) fresh membrane, and B) grafted membrane.

Fig. 7. The pure water flux of the ungrafted and grafted bi-layer YSZ membranes.

Fig. 8. Water flux as functions of the temperature of the feed side and the $\mathrm{NaCl}$ concentration.

Fig. 9. Overview of test results obtained for the YSZ bilayer membrane plotted as a function of the elapsed time. Shown are the average water fluxes, recorded at $80{ }^{\circ} \mathrm{C} / 20{ }^{\circ} \mathrm{C}$ temperature gradient. 


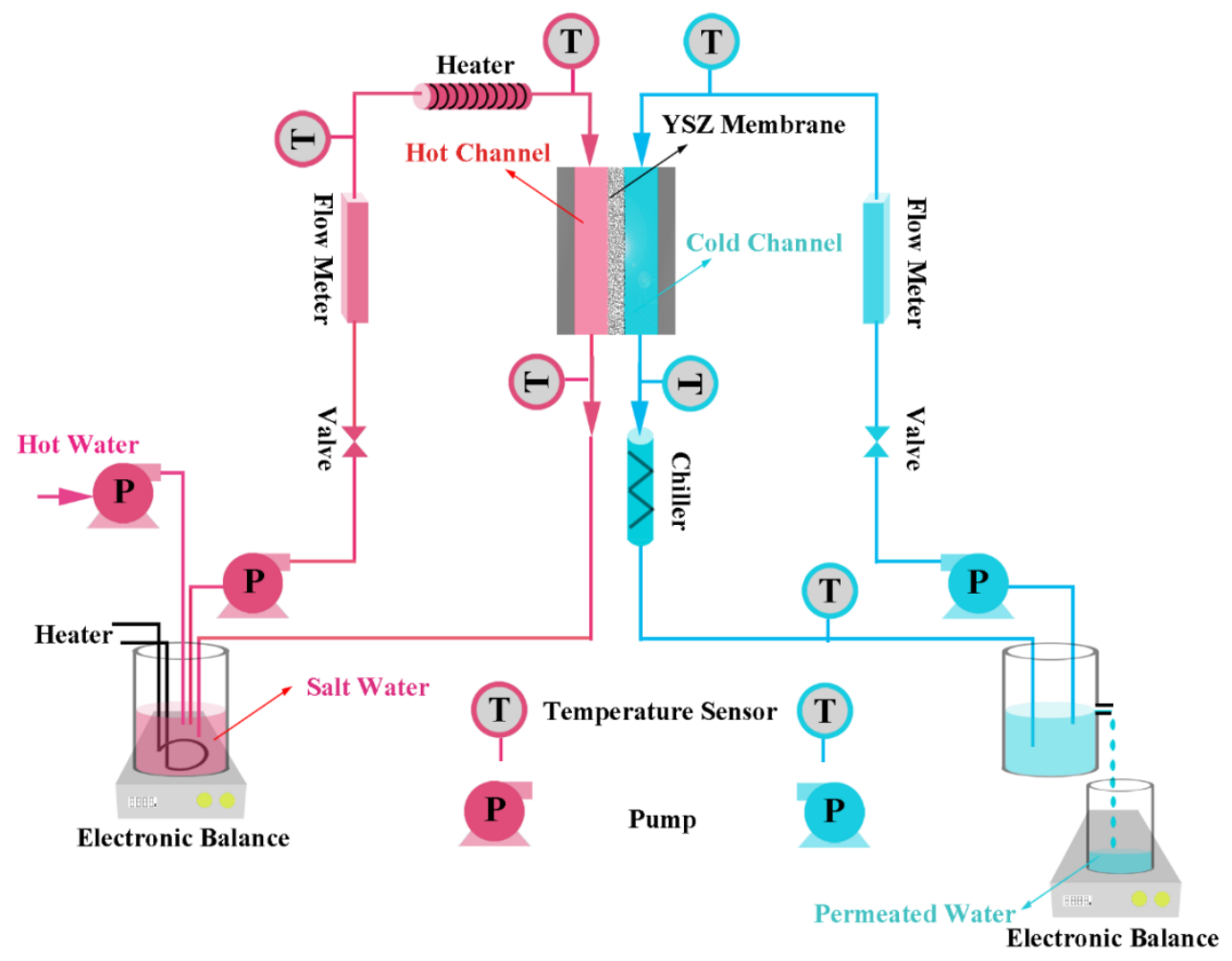

Fig.1. The piping and instrumentation diagram of the DCMD setup. 


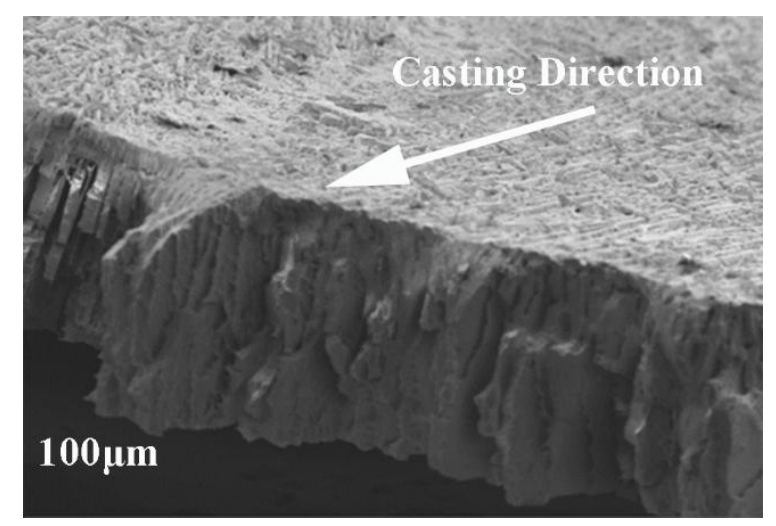

Fig. 2. The cross-sectional SEM image of the YSZ support pre-sintered at $1100{ }^{\circ} \mathrm{C}$. 

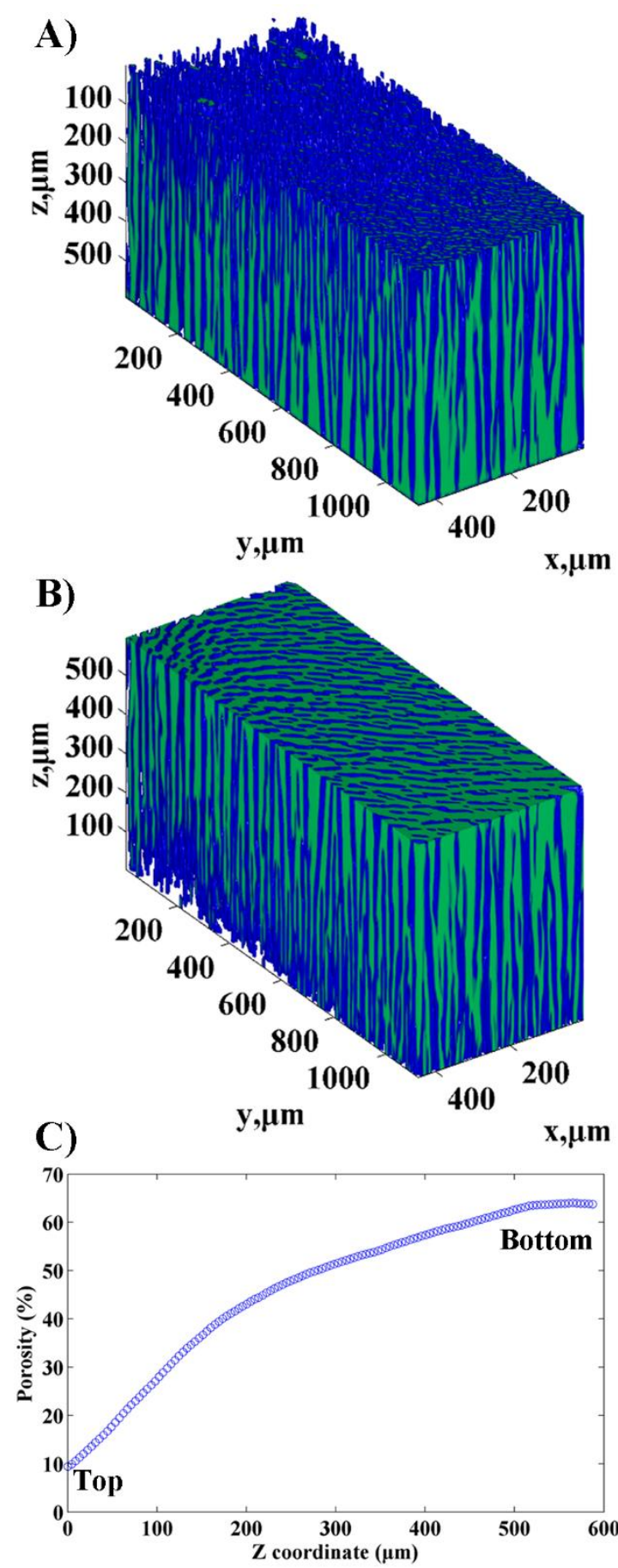

Fig. 3. Reconstructed 3D microstructural images of the YSZ support reconstructed from A) the top surface with micron-sized pores and B) the bottom surface with macro-pores. The blue and green regions represent solid and pore phases, respectively. C) Distribution of the local porosity along $z$-axis (thickness direction) from the top surface to the bottom surface. 


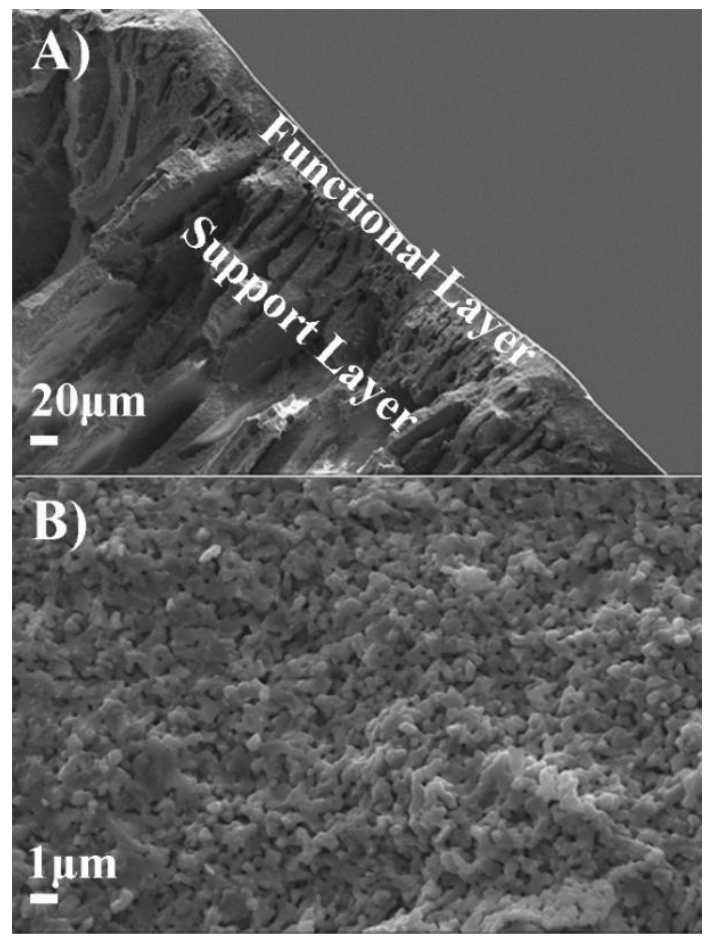

Fig. 4. SEM images of A) cross section of the bi-layered YSZ membrane and B) the functional layer. 


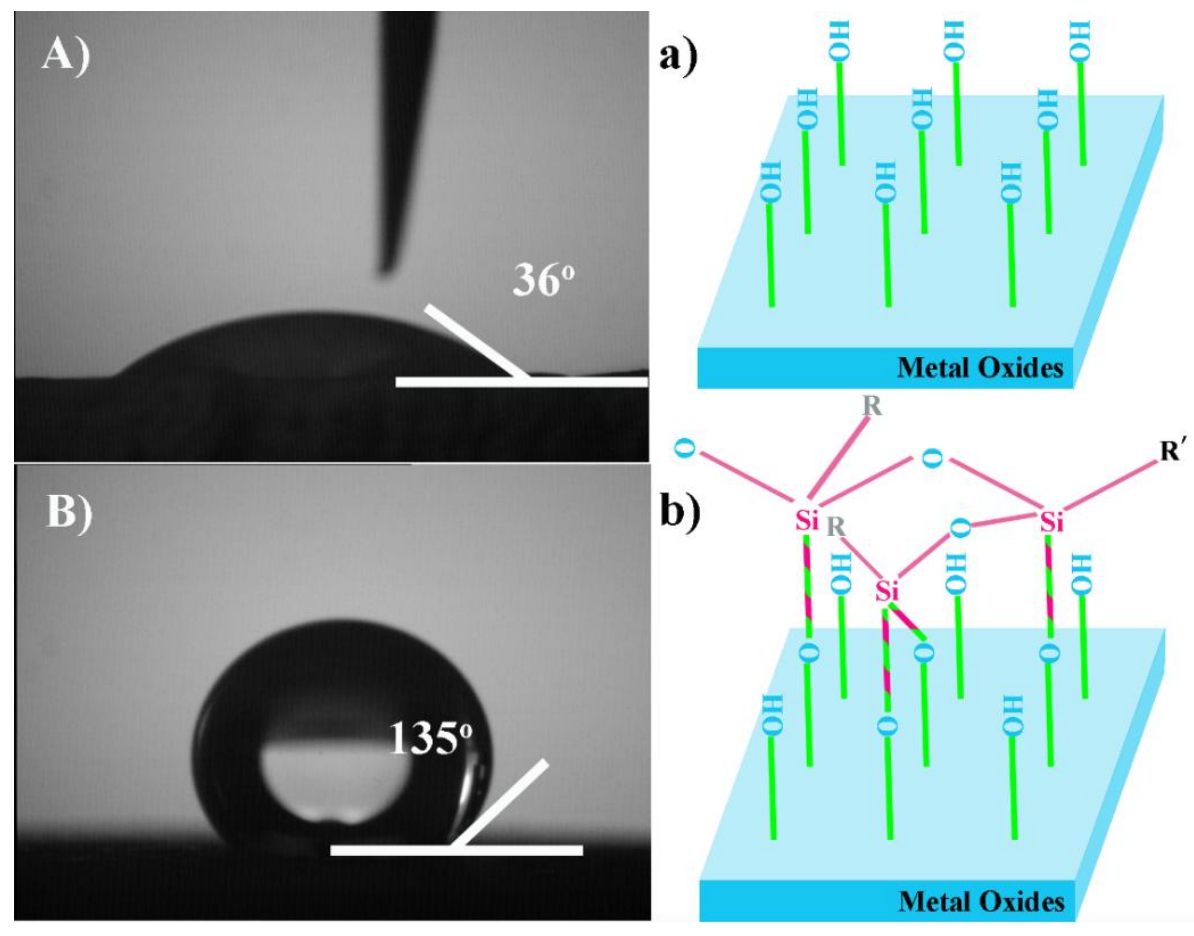

Fig. 5. Wetting behavior of the membranes, A-a) fresh membrane, B-b) grafted membrane, A-B) water contact angle, a-b) schematic diagram of the membrane surface. $R$ and $R^{\prime}$ both represent the hydrophobic groups (Fig. 5b). 

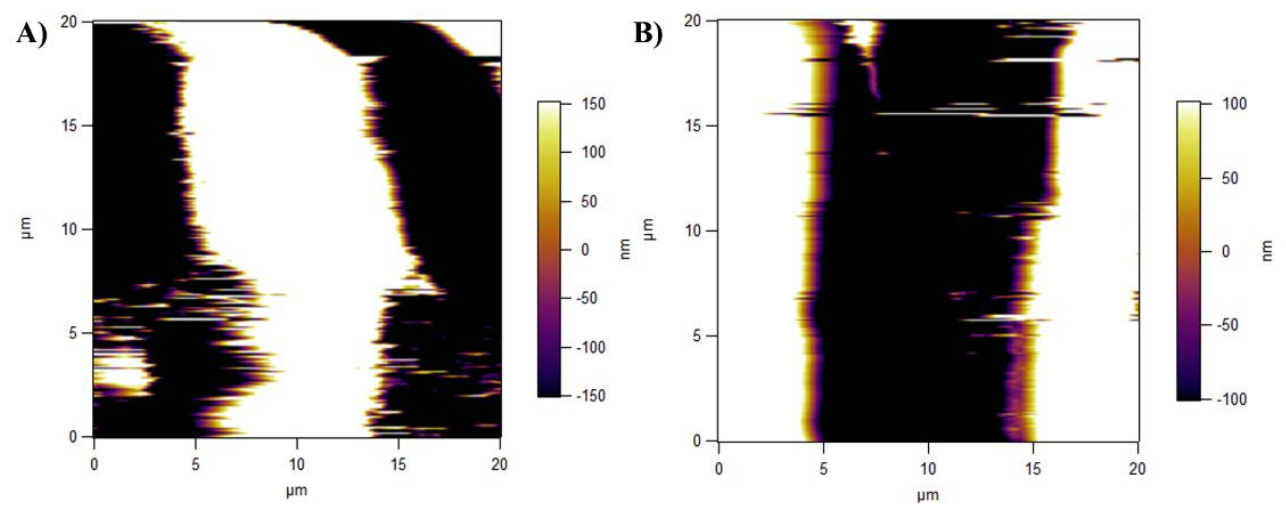

Fig. 6. AFM images of the membranes, A) fresh membrane and B) grafted membrane. 


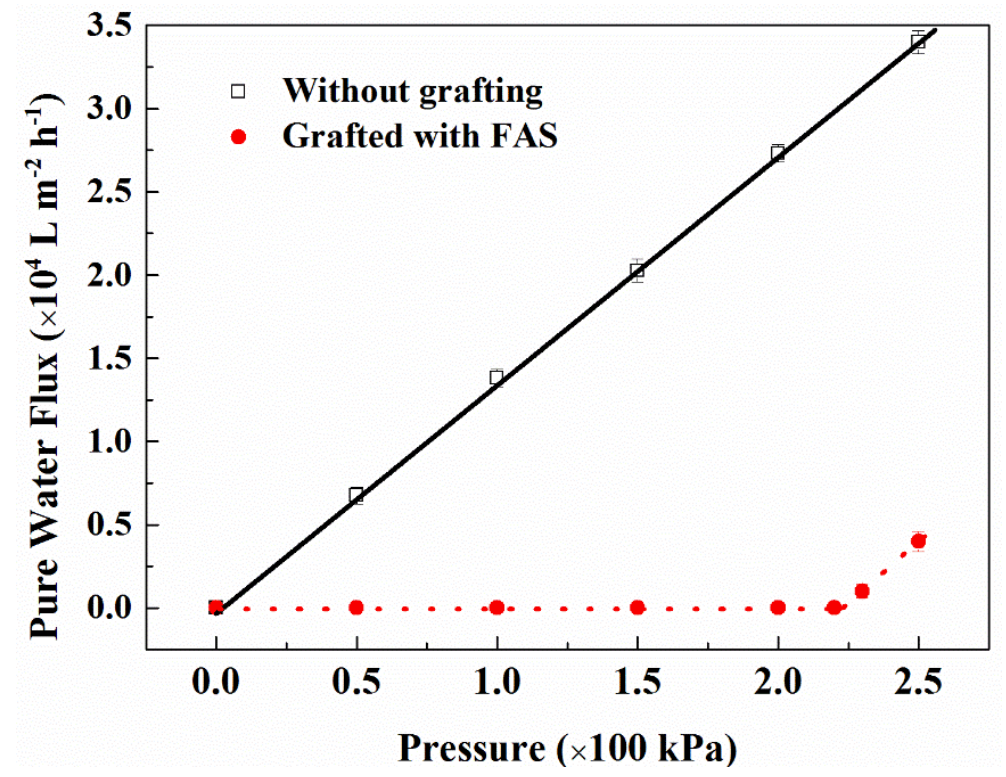

Fig. 7. The pure water flux of the ungrafted and grafted bi-layer YSZ membranes. 


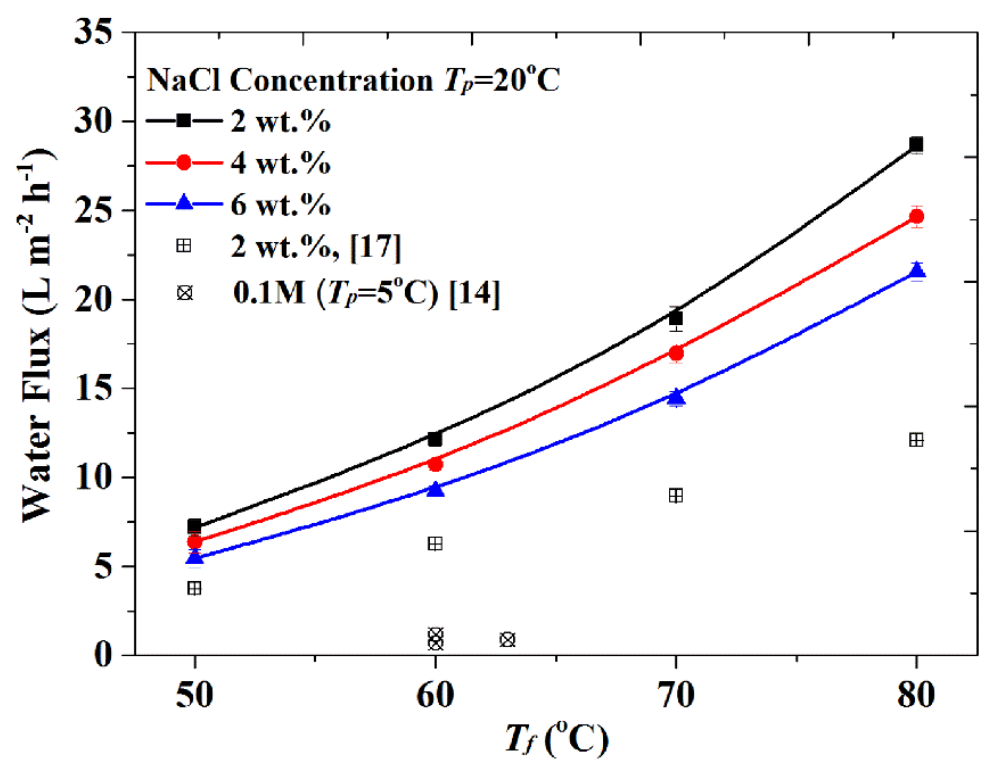

Fig. 8. Water flux as functions of the temperature of the feed side and the $\mathrm{NaCl}$ concentration. 


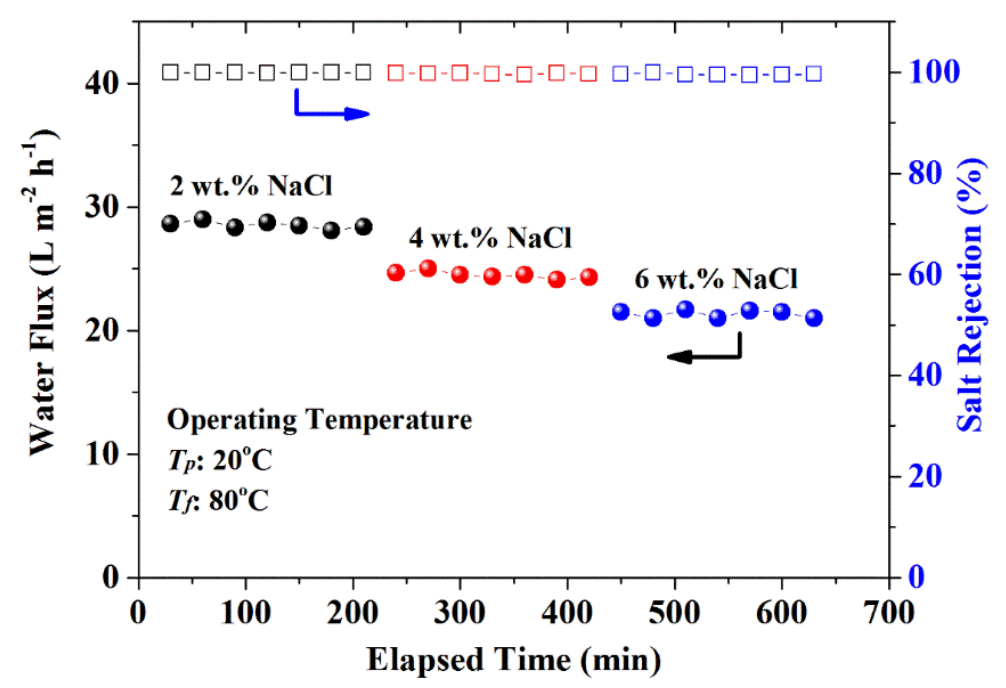

Fig. 9. Overview of test results obtained for the YSZ bilayer membrane plotted as a function of the elapsed time. Shown are the average water fluxes, recorded at $80{ }^{\circ} \mathrm{C} / 20{ }^{\circ} \mathrm{C}$ temperature gradient. 